\title{
The Impact of Applying IT and E-Learning in Economic Information Systems
}

\author{
Jihad A. A. Abu Al Sondos \\ Al Balqa Applied University, Faculty of Planning ad Management, Amman, Al Salt 19117, Jordan
}

\begin{abstract}
The purpose of this study was to investigate the impact of using the E-learning approach as well as IT technologies in the teaching process of Economics Information System (EIS) course to graduate students. Also, this study concentrates on two trends, the first one related to the befits of using E-learning approach in teaching EIS. The benefits of this approach are: Saving time for both the instructors and students; flexible scheduling for student since the course can be taken by the employee on time without interfering with his/her work, enable the students to access the material course to be learned at any time in the case of missing his/her lecture or session and improving the consistency concepts. The second related to the effect of information technology on the economic system. For example, we shall see what information is required to make markets efficient. Also, we shall see how this demand for information should be curtailed in increase privacy at the expense of efficiency. The important conclusion of this study can be shown as: Each student can view course content of EIS as well as the examination and homework announcement. Each student can view only his/her own grade not for other student. connection between students and their instructor will be done through a feedback form or e-mail. Students can evaluate his/her self through some quiz grade and the mistake question and finally the students have a capability of surveying all the previous examinations for the same course and subjects.
\end{abstract}

Key words: E- learning, EIS, FDA, MBA, E-R diagram

\section{INTRODUCTION}

When a person receives training or interaction by way of an electronic medium, it's E-learning. E-learning can employ: Web-based content, virtual classroom environments with live teacher classroom interaction and electronic collaboration through e-mail or internet discussion software. E-learning has significant advantages over traditional education and training such as:

1. Reduced costs; more people can be trained at one time and travel costs are eliminated.

2. Improved consistency; course material does not vary by instructor.

3. Flexible scheduling; course can be taken on an employees own time and not interfere with other work.

4. Improved timing; courses can be taken at any time and effectively used as just in time.

5. Streamlined logistics; an employee unavailable to attend a live training session has access to the same class in an electronic mode at any time.

According to what has been mentioned above, Elearning represents a strategy for using technology to enhance the learning process and for delivering and accessing interactive and distance learning curricula. When implemented successfully, E-learning programs can transfer the teaching process into a dynamic learning experience that stimulate students to develop their creative, critical and innovative thinking skills. Basic training on how to use computers and the Internet represents just one step in the entire e-learning process.

Finally, we would like to mention the purpose for choosing E-learning as a graduation project. E-learning is a newer term for phrases like web-based learning, online training, or distance learning. We can say that Elearning is generally defined as:

1. Content available anytime, 24 hours by 7 days.

2. Content accessible by a learner located anywhere in the world.

3. An environment that is learner-centered, one that is personalized to the individual and customized to the organization.

4. Network (Internet, LAN or WAN network) assisted.

5. The whole learning experience from assessment through testing and sometimes certification.

6. Including online administration called a learner Management System (LMS), a future topic for this page for handling registration, payment and charge backs and monitoring learner progress ${ }^{[1]}$.

To execute the purpose of E-learning projects in order to enhance the level of education and communication between the educational institutes and their students by using technology based education, we present this study which has a main goal concentrated on designing a web page on the Internet to help students study and monitor their EIS courses, where we focused 
on exporting this course in such a way that any student can use technology based learning techniques to enrich his/her curricula. The main page is divided into two sections: instructor's corner and student's corner. Many facilities were provided in this web page; student can check their homework, exams and examine their knowledge through a variety of quizzes and questions at the end of each chapter.

The work that verifies the above objectives consists of the following sections: section two describes the database schema. Section three was devoted to the description of our web page- every link and every design along with their functions as well as the important flowcharts that illustrates the admin. Login, student. login, homework and edit grades. Section four describes the EIS course contents. The study was terminated in section five with conclusions and future works.

Database schema of students, instructors and subjects: A database is a collection of information that is related to a particular subject or purpose, in this study our database is related to the student and accessed by the administrator (Instructor). Using Microsoft Access, we managed all our information from a several database files: (1) Admin; (2) Form; (3) Homework and (4) sub. Within each file, we have divided our data into separated storage containers called tables; where we view, add, delete and update data by using forms controlled by the instructor where he can find and retrieve the data he wants. One table is created to store one type of information that the instructor needs to track. The tables are described within each file in detail.

Firstly, for the administration file; this file contains several tables as: administration table, lesson table, student table, marks table. Each one of these tables consists of many fields with primary a key that distinguishes each table. There exists relationships between the tables since after we have set up different tables for each subject in the database, we define relationships between tables in order to join that information together. Figure 1 shows this relationship through a diagram called Entity-Relationship (E-R diagram).

Secondly, for the form file: this file contains one table named "form". This table is created to store the data concerned with the announcement of the exams which consists of fields for: the exam. name, month, year, hour, location and hall. Each field has a name, data type, size and indexed.

Thirdly, for the homework file: this file contains one table named "homework". This table is created to store the data concerned with the announcement of the homework which consists of field similar to that of the form file, also the structure of this field is similar to that of exam field.

Fourthly, for the sub file: this file contains one table named "feed". This table is concerned with the

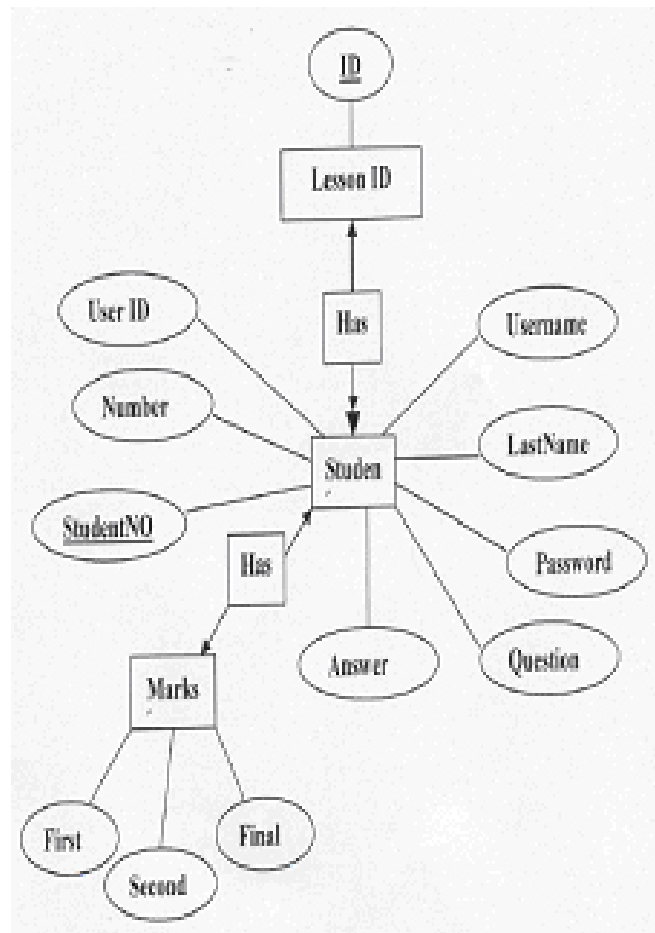

Fig. 1: E-R diagram for the designed database

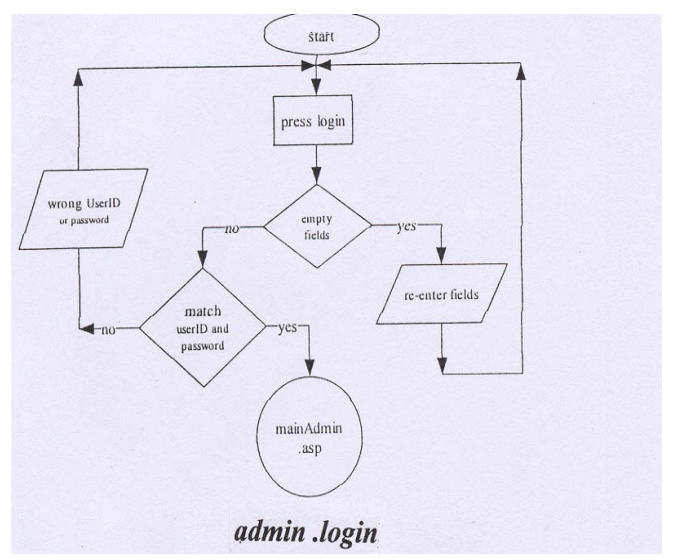

Fig. 2: Flowcharts that illustrate admin .login, Student. login, forget password

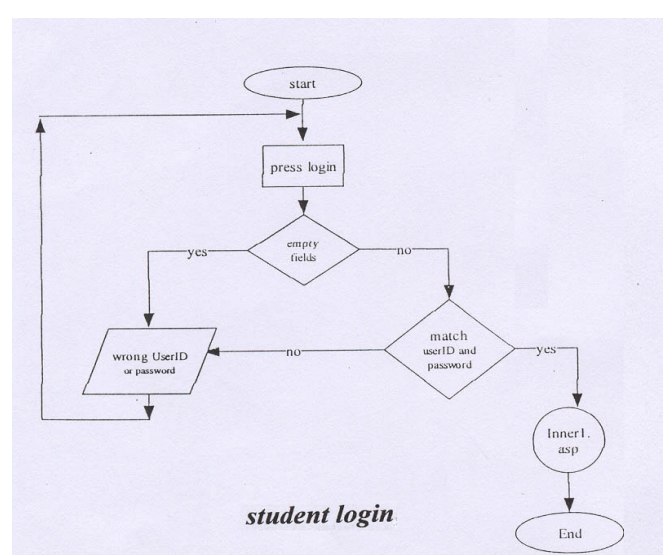

Fig. 2: Continued 


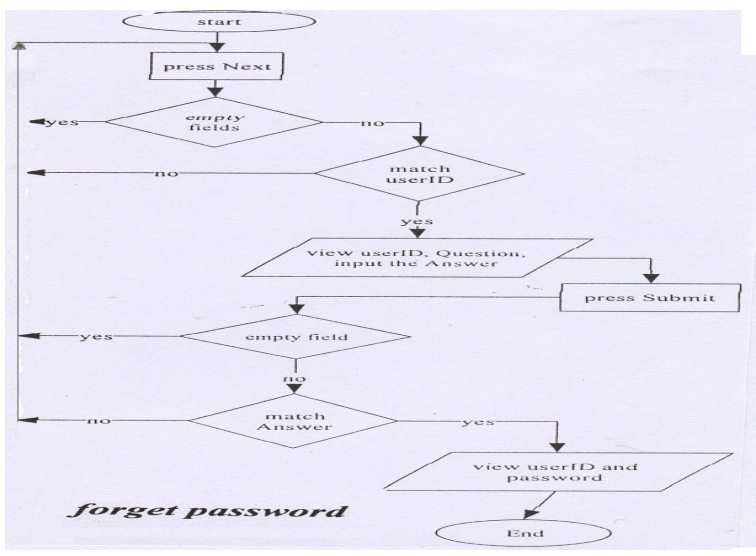

Fig. 2: Continued

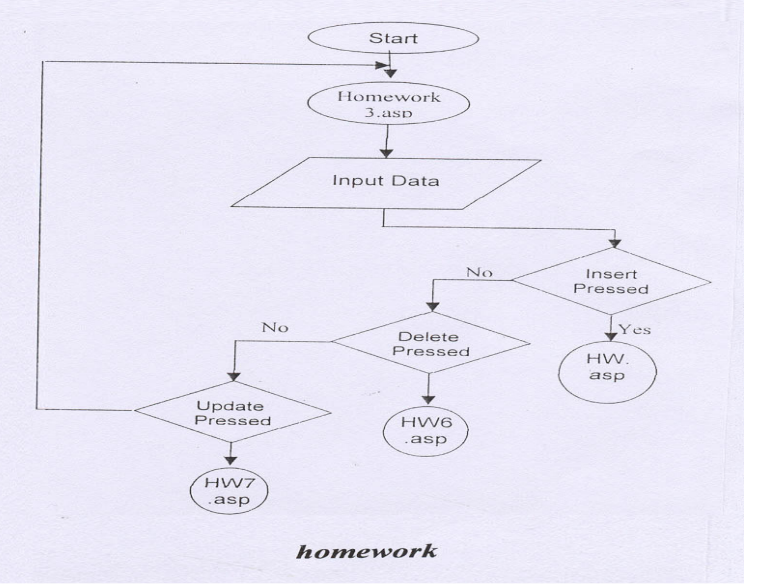

Fig. 2: Continued

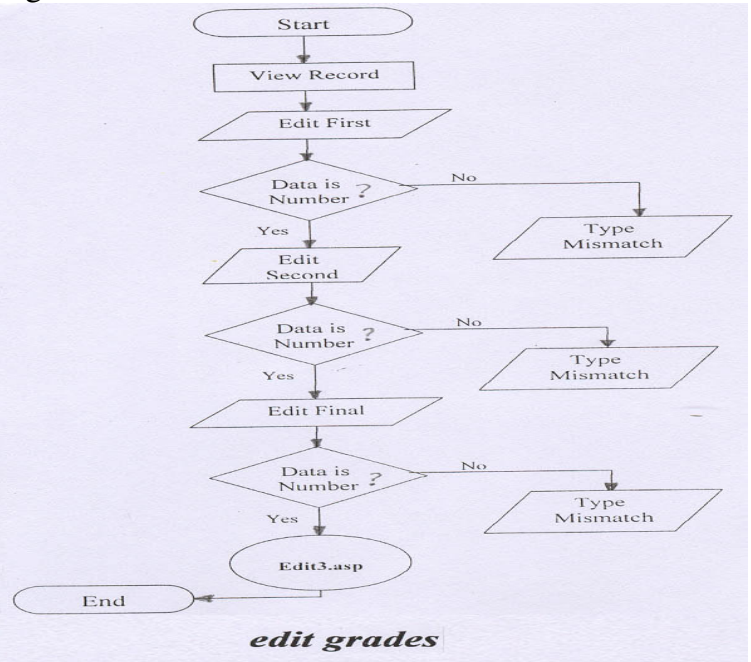

Fig. 3: Flowcharts that illustrate edit Grades and homework by instructor

feedback data entered by the student, where the instructor can view it and reply to his/her request according to some fields known by: message type, subject, comments, rating, gender, username. Also, each field has a name, data type and size.
Description of our web site for learning eis course: To construct a professional and complete website ${ }^{[2]}$, we have chosen the most appropriate software tools to design and connect different templates of databases in order to meet our objective defined by the following (a) A adobe PhotoShop: A adobe Photoshop 7.0 ME version, used to create the whole website and its navigation $\operatorname{bar}^{[3]}$. (b) Macromedia fireworks: Macromedia fireworks version 4.0: is a web centric tool for graphics used to build interactive web graphics ${ }^{[4]}$. (c) Macromedia dream weaver: Macromedia Dreamweaver version 0.6 , used to build and manage websites and internet applications ${ }^{[5,6]}$. (d) IIS (Internet Information Services): Web server from Microsoft, works as a server, plus has a integrated asp engine and it is a requirement in order to start our system ${ }^{[7]}$. (e) Microsoft Access: It's a database management program used to build powerful, customize enterprise data sources. The first section of the website is labeled as (1) home; this is our main login page which consists of user name and password for both the instructor and the student.

The proposed homepage is divided into numbered sections distributed according to the following: (1) Teacher corner's that is contains: an animation, user name, password and login. (2) Student corner's that is contains: an animation, user name, password, login and forgot password. The following numbering is a description for the above numbered sections: (a) user name; a field that displays the user name that was entered in (secret.asp) page. (b) question; a field with the question that was entered earlier by this specific student in (insertsecret.asp) page. (c) answer; a text field that the student has to fill with the right answer for the given question, which was also entered by him in page (insertsecret.asp) if the student didn't enter the answer, he won't be able to get his password. (d) submit; a submit button that will take the value entered in the answer field and compare it with the one that already exists in the database "Admin" table" student". If both values match, the student will enter (secret4.asp) page, if not he will remain on the same page. This page only returns values and displays the password of that student.

The second section of the website is labeled as (2) Main Admin; this is the page for the instructor where he can access the database tables. A menu of main admin.asp page contains links as follows: (a) exams; a link that take the instructor to (view2.asp) page. (b) Homework; a link that takes the instructor to (homework3.asp) page (c) student's records; a link that takes the instructor to (main Admin.asp) page in which there is a header with multilink concerning the student records. (d) Grade book; a link that takes the instructor to (Grades. asp) where a message appears to inform the instructor of the operations that he can apply on the grades for each student. (e) Change passwords; 
a link where the instructor can change the password he used to enter his (minAdmin.asp) page. (f) Feedback; A link that takes the instructor to (viewf.asp) page (g) logout; a link that takes the instructor out of the site back to (home. asp) page.

The flowchart that illustrates the edit grades and homework is shown in Fig. 3.

The third section of the website will be labeled as (3) inner 1; that page of the student is sent to when he/she enters and existing user name along with the right password.

The fourth section of the website will be labeled as (4) inner2; that page of the student is sent to when clicking on the martial link.

The fifth and final section of the website is concerned with security. In order to establish this property, there are some limitations should be followed given by: no user can enter the site unless he/she has a user name and password- if the user logged out and didn't close the browser, clicking the back button won't allow him/her to access any part of the site and use it.

Various access of economic information ystems (EIS): The contents of EIS is comprised from various chapters, which cover the main tracks of economic science as follows: Chapter one "What is the economics, the economic problem, economic methodology, making and using graphs, production, factors of production, growth of firms, demand and supply, elasticity, markets in action, utility and demand, possibilities, preferences and choices, organizing production, output and costs, equilibrium and disequilibrium". Chapter two" competition, monopoly, monopolistic competition and oligopoly, pricing and allocating factors of product, labour markets, capital and natural resources markets, uncertainty and information, market failure and public choice, inequality and redistribution, competition policy, externalities, the environment and knowledge". Chapter three:" a first look at macroeconomics, measuring GDP inflation and economic growth, aggregate demand and aggregate supply, aggregate demand and the multiplier, consumption and saving, investment, foreign trading, fiscal policy, money, banking and interest rates, monetary policy, fiscal and monetary interaction, growth policies, long-run and short-run aggregate supply. Chapter four: employment, wages and unemployment, capital and interest, economic growth, the business cycle, inflation, macroeconomic policy challenges, trading with the word, the balance of payments and the dollar.

\section{CONCLUSION AND FUTURE WORK}

An E-learning initiative creates dynamic education portals that save time and money to both parties where they can experience the world of virtual learning. Once the e-learning hubs are strengthened, they can act as the backbone of learning, support and resources for public school elementary, high school and local government institutions. With the right technology, E-learning enhances opportunities for interactive cooperative learning and the formation of communities of learners rather than relying on just the traditional face-to-face format. E-learning is a means of creating educational unification, connecting people who are unified in active learning communities by mastery of a shared knowledge and common educational goals and aspirations. Effective E-learning is rooted in a new paradigm for learning, key to the new learning process is the interactions among students themselves, the interaction between faculty and students and the collaboration in learning that results from these interactions.

For future work, we suggest some points can be extended to the previous work as: making an on- line quizzes and examination for the described EIS course on the previous web site. Enhance the proposed website to give a capability of discussion session for exchanging the student's knowledge and finally providing the facility of making some calculation of statistics for student grades and display it on a chart.

\section{REFERENCES}

1. Deitel, D. and Nieto, 2001. E- Business and ECommerce: How to Program. Prentice Hall.

2. Molley, E.H., 1998. Web by Design the Complete Guide. Sybex.

3. www.Adobe.com.

4. David, C. and R. Crowder, 2000. Macromedia Dream Weaver 3. Sybex.

5. Joseph, W.L., 2000. Dream weaver 4. Hungry Minds.

6. www.macromedia.com.

7. Deitel, D. and Nieto, 2002. Internet and World Web: How to Program. 2nd Edn. Prentice Hall. 